\title{
Estudo de fundente e argilito com potencial para uso em formulações de porcelanato
}

\section{(Study of flux and mudstone with potential for using in porcelainized stoneware tile compositions)}

\author{
F. S. Hoffmann, G. dos Santos, M. R. Morelli \\ ${ }^{1}$ Departamento de Engenharia de Materiais, Universidade Federal de S. Carlos - UFSCar, Rod. Washington \\ Luiz, km 235, C. P. 676, S. Carlos, SP 13565-905 \\ felipesh@gmail.com
}

\begin{abstract}
Resumo
O porcelanato se destaca no mercado atual de revestimentos cerâmicos por apresentar excelentes características técnicas e estéticas. No presente trabalho foram selecionadas matérias-primas cerâmicas tradicionais e adotada uma formulação padrão, convencionalmente reportada na literatura, visando a substituição do componente fundente (feldspato) por uma matéria-prima formadora de fase líquida em alta temperatura, e a substituição da fração argilosa por um argilito de menor refratariedade. O objetivo do estudo foi avaliar a utilização destas matérias-primas como alternativas técnicas e de menor custo, uma vez que, em uma massa de porcelanato, a quantidade de fundente é muito grande (representa aproximadamente $50 \%$ do total das matérias-primas utilizadas). A nefelina sienito foi à matériaprima natural substituta ao feldspato escolhida por pertencer à família dos feldspatóides e por possuir características físico-químicas semelhantes, sobretudo, elevada fundência. Para a substituição da fração argilosa foi escolhido um argilito de ocorrência natural, abundante na região de Santa Gertrudes, SP. As substituições ao feldspato e à fração argilosa ocorreram de maneira total e/ou parcial, por meio de combinações entre os fundentes e argilitos. As massas foram processadas a partir da mistura de pós, moagem a úmido, secagem, desaglomeração, compactação e queima. Além das curvas de gresificação, técnicas como dilatometria, medidas de porosidade aparente, ensaio de resistência mecânica à flexão a três pontos, microscopia eletrônica e difração de raios X foram utilizadas para a caracterização dos materiais após queima em diversas temperaturas. Os principais resultados mostraram que, a princípio, é possível a combinação das matérias-primas nefelina e argilito como material alternativo ao feldspato potássico e à argila S. Simão, pois elas proporcionam a gresificação em temperaturas mais baixas. Composições com ambas as matérias-primas apresentaram baixos valores de absorção de água $(<0,1 \%)$ e elevada resistência mecânica ( $>45 \mathrm{MPa})$, apesar de maior deformação piroplástica a $1150^{\circ} \mathrm{C}$.
\end{abstract}

Palavras-chave: porcelanato, matérias-primas, fundentes cerâmicos, argilitos.

\begin{abstract}
The porcelain tile is distinguished in the current market for ceramic tiles, with excellent technical and esthetic characteristics. In the present study traditional ceramic raw materials were selected and a standard formulation conventionally reported in the literature was adopted aiming to replace the melting phase (feldspar) of the composition for a raw material that forms liquid phase at high temperature, and replacement of the clay fraction by a mudstone of lower refractoriness. The aim of this study was to evaluate the use of these materials as alternative techniques and lower cost, since, in a mass of porcelain tile, the amount of flux is very large (representing approximately $50 \%$ of total raw materials used). The nepheline syenite was the natural raw material selected to replace the feldspar due to the fact that it belongs to the family of feldspathoids, and has similar physicochemical characteristics, therefore, a high fluxing efficiency. To replace the clay fraction was chosen a mudstone naturally occurring, abundant in the region of Santa Gertrudes, SP. Substitutions to the feldspar and clay fraction were completely and/or partially by means of combinations between the flux and mudstones. The masses were processed from the mixing of powders, wet milling, drying, disagglomeration, compaction and firing. In addition to the vitrification curves, techniques such as dilatometry, measurements of porosity, flexure strength test, electron microscopy and X-ray diffraction were used to characterize the material after firing at various temperatures. The results showed that, in principle, it is possible the combination of raw materials such as nepheline and mudstone to replace potassium feldspar and S. Simão clay, as they provide the vitrification at lower temperatures. Compositions with both materials showed lower values of water absorption $(<0.1 \%)$ and high mechanical strength (> $45 \mathrm{MPa}$ ), despite higher pyroplastic strain at $1150^{\circ} \mathrm{C}$.
\end{abstract}

Keywords: stoneware tile, raw materials, ceramic flux former.

\section{INTRODUÇÃO}

O Brasil ocupa lugar de destaque no segmento de Revestimento Cerâmico, sendo o segundo maior produtor mundial [1]. O setor vem apresentando um grande crescimento, chegando a uma produção de aproximadamente 775,7 milhões de $\mathrm{m}^{2}$ /ano. No país, o setor conta com 94 empresas e 117 plantas industriais instaladas, distribuídas em mais de 18 estados [2]. O crescente desenvolvimento mundial dos materiais cerâmicos nos últimos anos fez com que o 
conhecimento científico e tecnológico se tornasse cada vez mais necessário. A competitividade acirrada entre os fabricantes de revestimentos cerâmicos impõe medidas para redução de seus custos de produção e manutenção dos padrões de qualidade, atendendo as normas propostas pelos órgãos nacionais e internacionais de controle de qualidade [3].

\section{Porcelanato}

Dentro do grupo de cerâmicas para revestimento encontra-se o porcelanato, conhecido também como grês porcelanato, ou ainda granito cerâmico, ou grês fino porcelanato [4]. Tal nomenclatura se deve ao fato de que grês porcelanato deriva de "gres", que denomina materiais cerâmicos com estrutura compacta (caracterizados por uma fase cristalina imersa em uma matriz vítrea), e "porcellanato", termo que se refere às características técnicas deste produto similares a da porcelana [5]. No entanto, a partir da norma NBR 15463/2007 - Placas Cerâmicas Para RevestimentoPorcelanato [6], todas as denominações foram simplificadas e adota-se simplesmente a palavra porcelanato [5]. Os corpos de grês porcelanato são comumente constituídos de, aproximadamente, $55-65 \%$ de uma matriz vítrea, $20-25 \%$ de quartzo e $12-16 \%$ de mulita [7]. No início de sua fabricação, o porcelanato era produzido a uma temperatura de 1200 ${ }^{\circ} \mathrm{C}$ em longos períodos que variavam de 40 a $50 \mathrm{~h}$ sendo, portanto, um processo extremamente lento. Entre 1970 e 1980, com o contínuo desenvolvimento da tecnologia, conseguiu-se diminuir os ciclos de queima a valores muito menores por meio da alteração da formulação deste produto, sendo possível chegar, dependendo do formato, a valores da ordem de 35 a $90 \mathrm{~min}$. Esse novo ciclo de queima tornouse próximo aos encontrados em revestimentos cerâmicos tradicionais, que apresentam sua temperatura de queima variando de $1100{ }^{\circ} \mathrm{C}$ a $1250{ }^{\circ} \mathrm{C}$ [8]. Com a substituição dos antigos fornos a túnel por modernos fornos a rolo e a utilização de prensas hidráulicas cada vez mais potentes, peças dos mais variados tipos e tamanhos puderam ser fabricadas. Desde então, o porcelanato se apresenta como um produto altamente competitivo e versátil, podendo atingir vários setores e diferentes aplicações, atendendo tanto as características estéticas, como as características técnicas [9]. A classe dos porcelanatos apresenta três tipologias, de acordo com o acabamento dos produtos: natural (versão rústica), esmaltado (que recebe uma camada de vidrado sob sua superfície) e o polido (de superfície lisa e brilhante). Nesta terceira classe são retirados alguns décimos de milímetros do material da superfície da placa, realçando o aspecto estético sem modificar notavelmente as características mecânicas. Devido a suas características o porcelanato é motivo de atenção tanto de fabricantes nacionais e internacionais como também da comunidade científica, que procuram otimizar suas propriedades a fim de que, mesmo sendo constituído por matérias-primas essencialmente naturais, possa apresentar um desempenho comparável ao das cerâmicas técnicas, cujas tecnologias empregadas na fabricação são bem mais sofisticadas [10].

\section{Matérias-primas}

$\mathrm{Na}$ fabricação de revestimentos cerâmicos em geral, bem como para a fabricação de porcelanato, não existe uma única matéria-prima natural que venha a apresentar todas as características necessárias para que ocorra uma boa formulação: uma boa fundência, uma boa estabilidade dimensional, entre outras características. Portanto, se faz necessária a utilização de uma mistura de matérias-primas para se obter as características desejadas de uma massa a verde [11]. Para a fabricação do porcelanato, a mistura de matérias-primas utilizadas caracteriza-se por serem compostas por uma porcentagem variável de 30-50\% em peso de caulim e/ou argilas e uma proporção similar à anterior de feldspato sódico/potássico. São utilizados ainda, para a preparação da massa, outros tipos de matériasprimas, em uma escala menor, tais como o quartzo, argila

Tabela I - Composições típicas e analises químicas de massas cerâmicas para porcelanato [4]. [Table I - Typical compositions and chemical analysis of ceramic bodies for porcelainized stoneware tile [4].]

\begin{tabular}{ccccccc}
\hline Composições & 1 & 2 & 3 & 4 & 5 & 6 \\
\hline Argila & 38 & 41 & 45 & 35 & 30 & 35 \\
Feldspato & 40 & 16 & 35 & 45 & 50 & 38 \\
Caulim & 12 & 8 & - & - & - & 15 \\
Areia feldspática & 10 & 35 & 20 & 20 & 20 & 12 \\
$\mathrm{SiO}_{2}$ & 68,8 & 70,6 & 69,4 & 70,2 & 70,5 & 67,8 \\
$\mathrm{Al}_{2} \mathrm{O}_{3}$ & 19,9 & 18,6 & 19,0 & 18,3 & 17,1 & 20,4 \\
$\mathrm{~K}_{2} \mathrm{O}+\mathrm{Na}_{2} \mathrm{O}$ & 5,6 & 4,9 & 6,1 & 5,7 & 5,3 & 4,0 \\
$\mathrm{Fe}_{2} \mathrm{O}_{3}$ & 0,6 & 0,5 & 0,7 & 0,5 & 0,6 & 0,4 \\
$\mathrm{CaO}+\mathrm{MgO}$ & 0,5 & 0,5 & 0,6 & 0,7 & 1,2 & 0,5 \\
$\mathrm{P.F}$ & 3,8 & 3,6 & 3,3 & 3,5 & 3,8 & 3,7 \\
\hline
\end{tabular}


bentonítica, talco, entre outros, para se conseguir atingir determinadas propriedades do produto, ou facilitar a etapa de processamento. As matérias-primas comumente utilizadas para a fabricação do porcelanato, e os óxidos que estas irão fornecer ao sistema para posterior formação das fases são fornecidas na Tabela I.

A baixa porosidade desejada e, consequentemente, elevada resistência mecânica conferida aos produtos finais, fazem com que o feldspato esteja presente em grandes quantidades na massa de porcelanato tendo, portanto, um papel fundamental. Eles podem ser definidos como silico-aluminatos de metais alcalinos e alcalinos terrosos e, do ponto de vista químico, podem ser de quatro tipos [11]: feldspato potássico - $\left(\mathrm{K}_{2} \mathrm{O} \cdot \mathrm{Al}_{2} \mathrm{O}_{3} \cdot 6 \mathrm{SiO}_{2}\right)$, ortoclásio; feldspato sódico - $\left(\mathrm{Na}_{2} \mathrm{O} \cdot \mathrm{Al}_{2} \mathrm{O}_{3} \cdot 6 \mathrm{SiO}_{2}\right)$, albita; feldspato cálcico - $\left(\mathrm{CaO} \cdot \mathrm{Al}_{2} \mathrm{O}_{3} .2 \mathrm{SiO}_{2}\right)$, anortita; feldspato bárico $\left(\mathrm{BaO} . \mathrm{Al}_{2} \mathrm{O}_{3} .2 \mathrm{SiO}_{2}\right)$, anortita.

Para o porcelanato, o alto teor de álcalis (óxidos de metais alcalinos e alcalinos terrosos) proveniente dos feldspatos é extremamente importante, já que proporciona o aparecimento da primeira fase líquida formada durante a sinterização, sendo responsável pelo processo inicial da densificação, refletindo em baixa porosidade no produto final. A fusibilidade e a formação de eutéticos com outros elementos presentes possibilitam atingir a gresificação mesmo a temperaturas relativamente baixas, que são características dos minerais feldspáticos [5]. Junto aos feldspatos, há outra categoria de matérias-primas fundentes, pertencente ao grupo dos feldspatóides, como por exemplo, a nefelina, que é muito utilizada na fabricação de vidros e em alguns setores cerâmicos. Por ser uma fonte de álcalis, que diminui a fusibilidade da composição, melhora a capacidade fluxante e favorece o processo de vitrificação em temperaturas mais baixas. Vários materiais alternativos ao feldspato vêm sendo estudados por grupo de pesquisas e avaliados industrialmente, tais como o fonolito, filitos, talco e mais recentemente matérias-primas sintéticas como fritas e materiais reciclados como pó de vidro e de granito [11, 12]. No entanto, apesar dos diferentes tipos de álcalis presentes em cada um desses fundentes, a composição química total da matéria-prima substituinte influencia a microestrutura final do produto, indicando utilizações específicas para cada caso.

A nefelina sienito possui a fórmula química $\mathrm{NaAlSiO}_{4}$ (silicato de alumínio e sódio). Pode também apresentar potássio em sua fórmula. Constitui um importante mineral formador de rochas pobres em sílica, do grupo das rochas alcalinas. Seu nome deriva do grego "nephelus", que significa nuvem; dissolve-se em ácidos, gelatinizando e dando a este um aspecto enevoado. Apresentam-se como rochas ígneas insaturadas em sílica, nas cores branca, amarelada, incolor e avermelhada. Possui clivagem imperfeita, fratura irregular, e transparência translúcida. Dureza em escala Mohs varia entre 5 e 6 , e densidade em torno de $2,6 \mathrm{~g} / \mathrm{cm}^{3}$. Tais propriedades são semelhantes ao feldspato, logo a nefelina apresenta um grande potencial para utilização em massas de fabricação de porcelanato [12]. A nefelina é bastante usada na fabricação de praticamente todos os esmaltes cerâmicos, particularmente por causa da sua capacidade de atuar em ambos os ciclos, o de queima rápida e o convencional. Podese destacar que a vantagem da nefelina ante o feldspato consiste na sua ação fundente muito superior, além de produzir um fundido de menor viscosidade. Este fato está ligado à maior quantidade de óxidos fundentes $\left(\mathrm{K}_{2} \mathrm{O}+\mathrm{Na}_{2} \mathrm{O}\right)$, em torno de $14 \%$, o que reflete numa redução da temperatura de sinterização [7]. Se, por um lado, quando se utiliza a nefelina o produto apresenta um alto grau de densificação e aumento na resistência mecânica, por outro, o alto teor de óxido de ferro ( $>2 \%$ ), normalmente presente nesta matériaprima, dificulta sua utilização em cerâmicas que exijam um alto teor de brancura; a não ser que ela seja desmagnetizada.

Paralelamente, neste trabalho, busca-se a substituição parcial e/ou total da argila que entra na composição inicial dos porcelanatos. As argilas são compostas por uma infinidade de componentes, cuja característica principal é a plasticidade. A argila plástica é composta basicamente de argilominerais, como a caulinita, a ilita, a montmorilonita e a esmectita, e outros minerais não argilosos, como o quartzo, o feldspato, micas e matéria orgânica. Uma argila comumente utilizada na região sudeste para a formulação de cerâmica branca é a argila S. Simão, também conhecida como uma argila tipo ball-clay. Tal classe de argila apresenta como fases principais o quartzo e a caulinita. $\mathrm{O}$ argilito escolhido para a substituição da argila ball-clay possui ocorrência natural, encontrado no pólo de Santa Gertrudes, SP. O argilito de Santa Gertrudes, por sua vez, é composto por quartzo, ortoclásio, albita, hematita, ilita e calcita. Logo, é uma matéria-prima mais fundente e que apresenta cor de queima avermelhada, decorrente dos íons $\mathrm{Fe}^{2+}$ encontrado na hematita. Em contrapartida, é uma matéria-prima de menor valor agregado, o que leva a possibilidade de redução de custo do produto final.

Assim, o objetivo principal foi estudar composições com dois diferentes fundentes, o feldspato e a nefelina sienito, comparativamente a uma composição tradicional de porcelanato contendo somente feldspato, além da possibilidade de substituição da argila S. Simão por um argilito menos nobre (argilito de Santa Gertrudes). Para isto, foram analisadas as características cerâmicas após queima de composições com substituição total e parcial do feldspato, bem como de combinações contendo ou argila S. Simão ou argilito de Santa Gertrudes.

\section{MATERIAIS E MÉTODOS}

As matérias-primas que foram utilizadas para a realização deste trabalho são materiais comerciais que apresentam análise química definida, exceto as argilas, para que as composições possam ser preparadas com maior reprodutibilidade. As composições que foram avaliadas são baseadas em uma composição padrão para porcelanato [13], que consiste em: $45 \%$ em peso de feldspato potássico (ortoclásio), $35 \%$ em peso de argila caulinítica, $15 \%$ em peso de caulim, $7 \%$ em peso de quartzo, e $3 \%$ em peso de talco. 
Tabela II - Análises químicas das matérias-primas (\% em peso) utilizadas nas composições de porcelanato. [Table II - Chemical analysis of raw materials (wt \%) used in the compositions of porcelainized stoneware tile.]

\begin{tabular}{cccccccccc}
\hline Matéria-prima & $\mathrm{SiO}_{2}$ & $\mathrm{Al}_{2} \mathrm{O}_{3}$ & $\mathrm{Fe}_{2} \mathrm{O}_{3}$ & $\mathrm{CaO}$ & $\mathrm{Na}_{2} \mathrm{O}$ & $\mathrm{K}_{2} \mathrm{O}$ & $\mathrm{TiO}_{2}$ & $\mathrm{MgO}$ & $\mathrm{PF}$ \\
\hline Feldspato & 65,17 & 19,09 & 0,03 & 0,10 & 2,85 & 11,63 & 0,01 & 0,02 & 0,68 \\
Nefelina & 63,22 & 19,85 & 0,26 & 0,46 & 7,10 & 7,89 & 0,14 & 0,02 & 1,06 \\
Argila S. Simão & 54,44 & 29,91 & 1,08 & 0,41 & 0,03 & 0,50 & 1,02 & 0,09 & 12,42 \\
Argilito S. Gertrudes & 68,18 & 14,2 & 5,31 & 0,72 & 2,66 & 3,59 & 0,61 & 1,88 & 2,69 \\
Caulim & 45,16 & 39,24 & 0,88 & 0,01 & 0,11 & 1,08 & 0,07 & 0,03 & 13,35 \\
Quartzo & 98,93 & 0,50 & 0,04 & 0,03 & 0,07 & 0,17 & 0,01 & $<0,01$ & 0,22 \\
Talco & 62,92 & 0,59 & 0,24 & 0,02 & $<0,01$ & $<0,01$ & 0,01 & 30,95 & 5,26 \\
\hline
\end{tabular}

Nota: as matérias-primas feldspato, argila, caulim, quarto e talco são de procedência da Minasolo S.A. e a nefelina desmagnetizada $\left(\mathrm{Fe}_{2} \mathrm{O}_{3}<2 \%\right)$ da Ematec S.A..

As análises químicas das matérias-primas utilizadas são apresentadas na Tabela II, de acordo com os fornecedores.

Preparação dos corpos de prova: inicialmente, as matérias-primas foram pesadas segundo as composições previamente estabelecidas, misturadas à água e ao defloculante $(0,3 \%$ em peso de hexametafosfato de sódio), e moídas em moinho de bolas de alumina (relação 45/55 sólido água) durante um período de $4 \mathrm{~h}$. Depois da moagem cada barbotina foi seca em estufa a $110^{\circ} \mathrm{C}$. Após a secagem, as massas foram desagregadas em almofariz e passadas em peneira de malha 45 mesh; $8 \%$ de água foram adicionados para a granulação em peneira 18 mesh, para auxiliar na etapa de prensagem. Os pós foram acondicionados por um período de $24 \mathrm{~h}$ para uma completa homogeneização da umidade. Em seguida as misturas de matérias-primas foram prensadas em moldes metálicos $(6 \mathrm{~cm}$ de comprimento $\mathrm{x}$ $2 \mathrm{~cm}$ de largura) com utilização de uma prensa hidráulica; foi utilizada a pressão de compactação de $240 \mathrm{kgf} / \mathrm{cm}^{2}$. As amostras obtidas foram queimadas em forno elétrico ao ar sob diferentes ciclos de queima, e resfriadas naturalmente até a temperatura ambiente. Foi adotado um ciclo de queima com uma taxa de aquecimento de $10{ }^{\circ} \mathrm{C} / \mathrm{min}$, com um patamar de $10 \mathrm{~min}$, nas seguintes temperaturas: 950, 1000, $1050,1100,1150$ e $1175^{\circ} \mathrm{C}$. Após as queimas, as amostras foram caracterizadas fisicamente quanto à densidade e porosidade aparente, absorção de água, retração linear, e resistência mecânica à flexão. A análise microestrutural foi feita em superfícies de fratura por microscopia eletrônica de varredura e a análise de difração de raios $\mathrm{X}$ realizada em amostras retiradas do mesmo corpo-de-prova após desagregação em almofariz de ágata.

A Tabela III apresenta as composições de interesse estudadas.

Caracterização das matérias-primas e composições: as matérias-primas foram caracterizadas quanto à análise química, por meio da técnica de fluorescência de raios $\mathrm{X}$, e as misturas de pós das composições por sedimentometria para obtenção das curvas de distribuição de tamanho de partículas. Os corpos-de-prova prensados também foram analisados por dilatometria para observação das temperaturas de início de sinterização de cada composição como função da alteração dos materiais fundentes.

Tabela III - Formulações básicas de porcelanato, onde o fundente feldspato foi substituído inteira e proporcionalmente por nefelina, e a argila S. Simão foi substituída pelo argilito de Santa Gertrudes, de forma a gerar as diferentes reformulações (\% em peso).

[Table III - Basic formulations of porcelainized stoneware tile, where feldspar was replaced whole and proportionately by nepheline, and the S. Simão clay was replaced by the Santa Gertrudes mudstone, to generate the different reformulations (wt\%).]

\begin{tabular}{cccccccc}
\hline Composição & Feldspato & Nefelina & Argila S. Simão & Argila S. Gertrudes & Caulim & Quartzo & Talco \\
\hline 1 & 45 & 0 & 30 & 0 & 15 & 7 & 3 \\
2 & 22,5 & 22,5 & 30 & 0 & 15 & 7 & 3 \\
3 & 0 & 45 & 30 & 0 & 15 & 7 & 3 \\
4 & 45 & 0 & 0 & 30 & 15 & 7 & 3 \\
5 & 33,75 & 11,25 & 0 & 30 & 15 & 7 & 3 \\
6 & 22,5 & 22,5 & 0 & 30 & 15 & 7 & 3 \\
7 & 11,25 & 33,75 & 0 & 30 & 15 & 7 & 3 \\
8 & 0 & 45 & 0 & 30 & 15 & 7 & 3 \\
\hline
\end{tabular}


Caracterização das amostras após a queima: os corposde-prova das diversas composições foram caracterizados após a queima por medidas de densidade e porosidade aparente, absorção de água, retração linear de queima (curva de gresificação), resistência mecânica a flexão a três pontos e deformação piroplástica. Para a análise da formação de fases e observação do desenvolvimento microestrutural utilizouse das técnicas de difratometria de raios $\mathrm{X}$ e microscopia eletrônica de varredura, respectivamente.

\section{RESULTADOS E DISCUSSÃO}

Este trabalho envolve várias composições visando à caracterização de massas de porcelanato onde o feldspato, usualmente utilizado, foi substituído total e parcialmente por nefelina, concomitantemente a substituição da argila S. Simão por argilito de Santa Gertrudes.

Distribuição do tamanho de partículas: procurou-se por meio da moagem, ainda que por um tempo longo (24 h), garantir que toda massa (mistura de matérias-primas da formulação) estivesse passante em peneira de malha 325 mesh $(<45 \mu \mathrm{m})$, ou seja, moagem fina sem resíduo, como recomendado pelos fabricantes de porcelanato. Tamanhos característicos às proporções em que 10, 50 e $90 \%$ do material é passante, foram determinados por sedimentometria e representados respectivamente por $\mathrm{D}_{10}$, $\mathrm{D}_{50}$ e $\mathrm{D}_{90}$. Os resultados estão apresentados na Tabela IV.

Tabela IV - Distribuição do tamanho de partículas das massas de porcelanato das composições em que se utilizaram os fundentes feldspato e nefelina, argila S. Simão e argilito de Santa Gertrudes, puros e combinados (\% em peso).

[Table IV - Particle size distribution of powders of porcelainized stoneware tile porcelain compositions with pure and combined feldspar and nepheline, S. Simão clay and S. Gertrudes mudstone (weight\%).]

\begin{tabular}{cccc}
\hline Composição & $\begin{array}{c}\mathrm{D}_{90} \\
(\mu \mathrm{m})\end{array}$ & $\begin{array}{c}\mathrm{D}_{50} \\
(\mu \mathrm{m})\end{array}$ & $\begin{array}{c}\mathrm{D}_{10} \\
(\mu \mathrm{m})\end{array}$ \\
\hline 1 & 19,0 & 5,2 & 1,1 \\
2 & 19,5 & 7,5 & 3,5 \\
3 & 20,0 & 7,3 & 4,4 \\
4 & 20,0 & 7,5 & 2,5 \\
5 & 20,0 & 7,1 & 1,8 \\
6 & 30,0 & 10,0 & 4,3 \\
7 & 25,0 & 7,0 & 3,0 \\
8 & 25,5 & 7,0 & 2,0 \\
\hline
\end{tabular}

Nota: $D_{10}$ é o diâmetro no qual o material possui $10 \%$ de partículas com valor inferior a este; $D_{50}$ representa o diâmetro médio e $D_{90}$ o diâmetro no qual o material possui $90 \%$ de particulas com valor inferior a este.

Pode-se observar que, embora se tenha mantido as mesmas condições experimentais durante a etapa de mistura e moagem das matérias-primas, as composições contendo o argilito Santa Gertrudes apresentaram mais larga distribuição e maior tamanho médio de partículas do que as massas com argila São Simão. Este fato se deve a maior dureza do argilito em relação à argila de queima branca.

Curvas de gresificação: este trabalho envolve várias composições visando à caracterização de massas de porcelanato onde o feldspato, usualmente utilizado, foi substituído total e parcialmente por nefelina, concomitante à substituição da argila S. Simão pelo argilito de Santa Gertrudes. Desta forma, as curvas de gresificação são apresentadas para cada composição descrita anteriormente.

Composição $100 \%$ feldspato e $100 \%$ argila S. Simão (ou composição 1): esta composição é considerada como sendo uma composição teórica padrão encontrada na literatura [14], constituída por $45 \%$ feldspato, $30 \%$ argila S. Simão, $15 \%$ caulim, $7 \%$ quartzo e $3 \%$ talco, sendo reproduzida neste trabalho. Por meio da análise da curva de gresificação da composição 1 , pode-se notar que não houve nenhum aumento substancial de sua retração linear e uma diminuição em sua absorção de água até a temperatura em torno de $1000{ }^{\circ} \mathrm{C}$ (Fig. 1). A partir desta temperatura, os valores de retração e absorção começam a se modificar e este comportamento se torna mais acentuado a $1100{ }^{\circ} \mathrm{C}$, quando ocorre uma queda na absorção e aumento da retração, possivelmente devido à presença da fase líquida oriunda do feldspato.

\section{Composição 1}

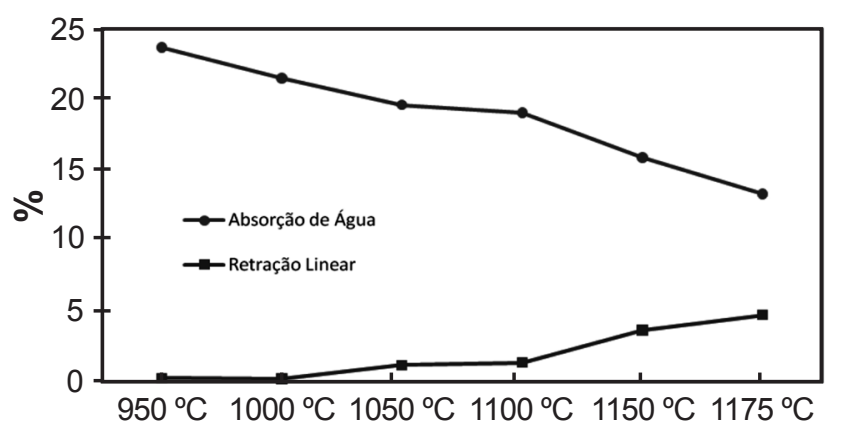

Figura 1: Gráfico de gresificação da massa de porcelanato de composição 1 (100\% feldspato e 100\% argila S. Simão).

[Figure 1: Vitrification curves of porcelainized stoneware tile body of composition 1 (100\% feldspar and 100\% S. Simão clay).]

Composição $50 \%$ feldspato, $50 \%$ nefelina e $100 \%$ argila S. Simão (ou composição 2): pode-se analisar por meio da curva de gresificação para esta composição, Fig. 2, mais uma vez um aumento da retração linear e uma diminuição dos valores de absorção de água com o aumento da temperatura de queima. Porém temperaturas maiores ainda são necessárias para a obtenção de menores valores de absorção de água, necessárias para obedecer à norma técnica dos porcelanatos.

Composição 100\% nefelina e 100\% argila S. Simão (ou composição 3): a curva de gresificação desta composição, Fig. 3, mostra a maior fundência da nefelina em relação ao feldspato (Fig. 1), não só pelo maior valor de retração linear e, principalmente, pelo menor valor de absorção de água, 


\section{Composição 2}

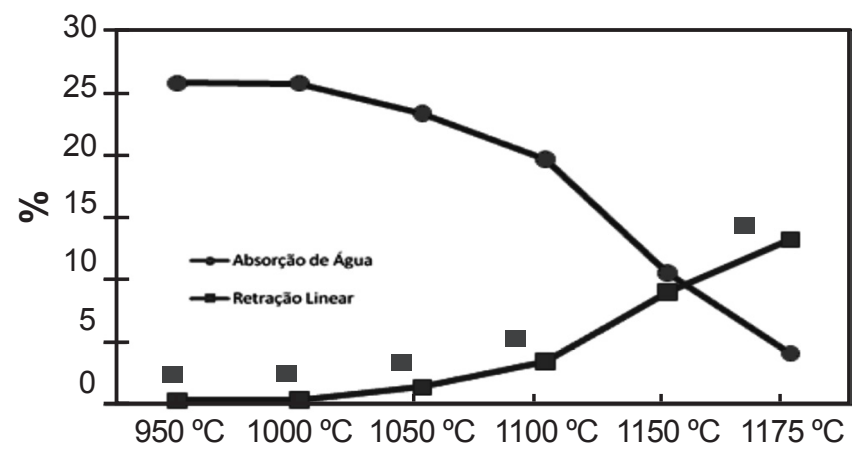

Figura 2: Gráfico de gresificação da massa de porcelanato de composição 2 (50\% feldspato, 50\% nefelina e 100\% argila S. Simão).

[Figure 2: Vitrification curves of porcelainized stoneware tile body of composition 2 (50\% feldspar, 50\% nepheline and 100\% S. Simão clay).]

\section{Composição 3}

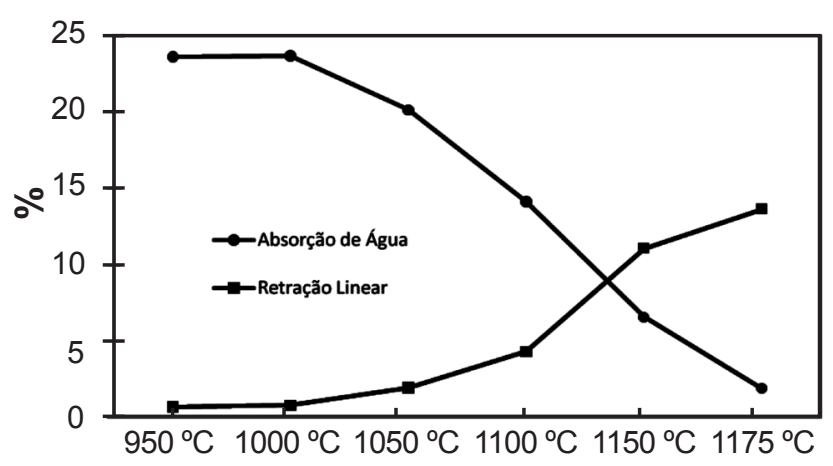

Figura 3: Gráfico de gresificação da massa de porcelanato de composição 3 (100\% nefelina e 100\% argila S. Simão).

[Figure 3: Vitrification curves of porcelainized stoneware tile body of composition 3 (100\% nepheline and 100\% S. Simão clay).]

mas pelo deslocamento do ponto de cruzamento das curvas numa menor temperatura. No entanto, vale observar que nenhuma modificação ocorre até a temperatura de $1000{ }^{\circ} \mathrm{C}$.

Composição 100\% feldspato e 100\% argilito Santa Gertrudes (ou composição 4): observando a curva de gresificação para esta composição, Fig. 4, pode-se notar que o aumento da retração linear e a diminuição da absorção de água, já ocorrem a $950^{\circ} \mathrm{C}$, indicando a maior capacidade de fundência e/ou reatividade da matéria-prima argilito Santa Gertrudes, quando comparada à argila S. Simão. Nota-se também baixíssima absorção de água para ciclo de queima com patamar em $1175^{\circ} \mathrm{C}$.

Composição $75 \%$ feldspato, 25\% nefelina e 100\% argilito Santa Gertrudes (ou composição 5): por meio da análise da curva de gresificação da composição 5, Fig. 5, observase a partir de patamares de queima superiores a $1000{ }^{\circ} \mathrm{C}$ uma acentuada queda da absorção de água dos corpos, e um elevado aumento da retração linear de queima. Desta forma, o ponto de cruzamento das curvas correspondentes a

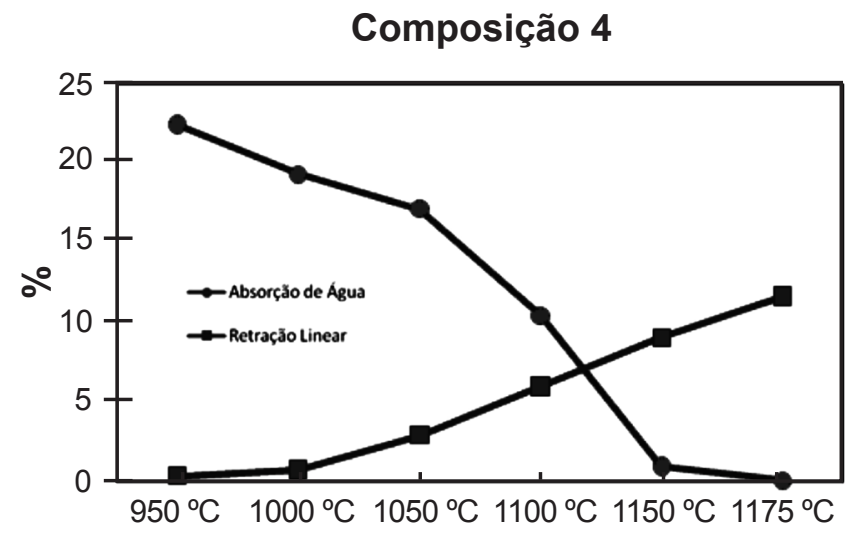

Figura 4: Gráfico de gresificação da massa de porcelanato de composição 4 (100\% feldspato e 100\% argilito Santa Gertrudes). [Figure 4: Vitrification curves of porcelainized stoneware tile body of composition 4 (100\% feldspar and 100\% Santa Gertrudes mudstone).]

\section{Composição 5}

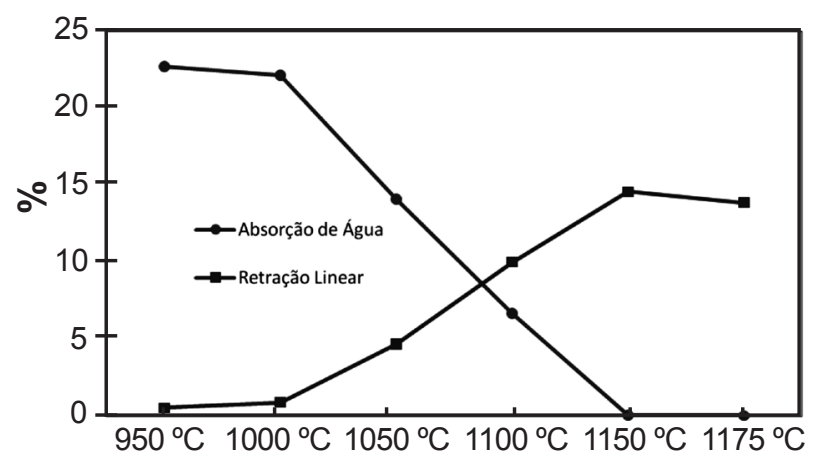

Figura 5: Gráfico de gresificação da massa de porcelanato de composição 5 (75\% feldspato, $25 \%$ nefelina e $100 \%$ argilito Santa Gertrudes).

[Figure 5: Vitrification curves of porcelainized stoneware tile body of composition 5 (75\% feldspar, 25\% nepheline and 100\% Santa Gertrudes mudstone).]

essa formulação foi deslocado para uma temperatura ainda menor. Baixíssima absorção de água também é observada a partir de $1150{ }^{\circ} \mathrm{C}$.

Composição 50\% feldspato, 50\% nefelina e 100\% argilito Santa Gertrudes (ou composição 6): analisando a curva de gresificação para esta composição, Fig. 6, é possível observar comportamento muito parecido com a composição 5. Queda abrupta da absorção de água a partir de $1000{ }^{\circ} \mathrm{C}$, com valores muito reduzidos a partir de $1150{ }^{\circ} \mathrm{C}$.

Composição 25\% feldspato, 75\% nefelina e 100\% argilito Santa Gertrudes (ou composição 7): por meio da análise da curva de gresificação da composição 7, Fig. 7, observa-se um caráter ainda mais acentuado na queda da absorção de água dos corpos, com elevado aumento da retração linear de queima. Assim como as outras composições contendo argilito, esta apresenta reduzida absorção de água a partir de $1150^{\circ} \mathrm{C}$.

Composição 100\% nefelina e 100\% argilito Santa 


\section{Composição 6}

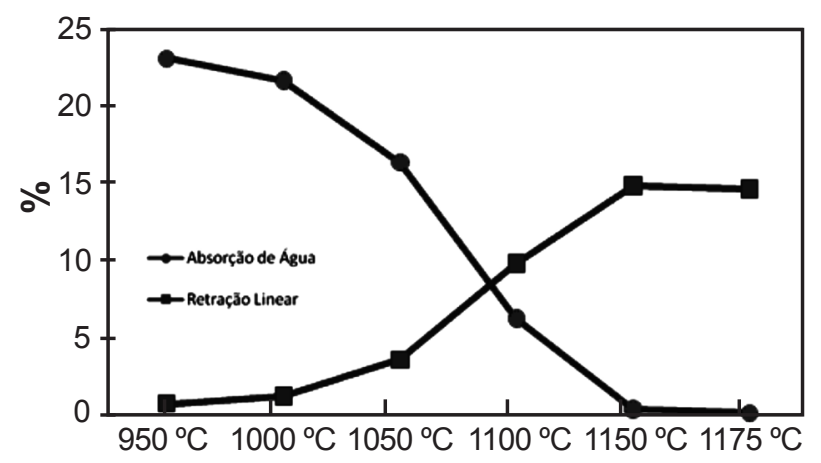

Figura 6: Gráfico de gresificação da massa de porcelanato de composição 6 (50\% feldspato, 50\% nefelina e 100\% argilito Santa Gertrudes).

[Figure 6: Vitrification curves of porcelainized stoneware tile body of composition 6 (50\% feldspar, 50\% nepheline and 100\% Santa Gertrudes mudstone).]

\section{Composição 7}

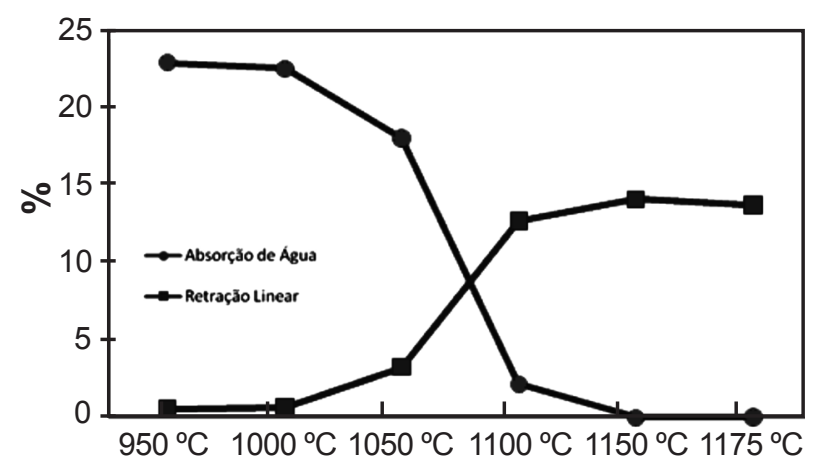

Figura 7: Gráfico de gresificação da massa de porcelanato de composição 7 (25\% feldspato, 75\% nefelina e 100\% argilito Santa Gertrudes).

[Figure 7: Vitrification curves of porcelainized stoneware tile body of composition 7 (25\% feldspar, 75\% nepheline and 100\% Santa Gertrudes mudstone).]

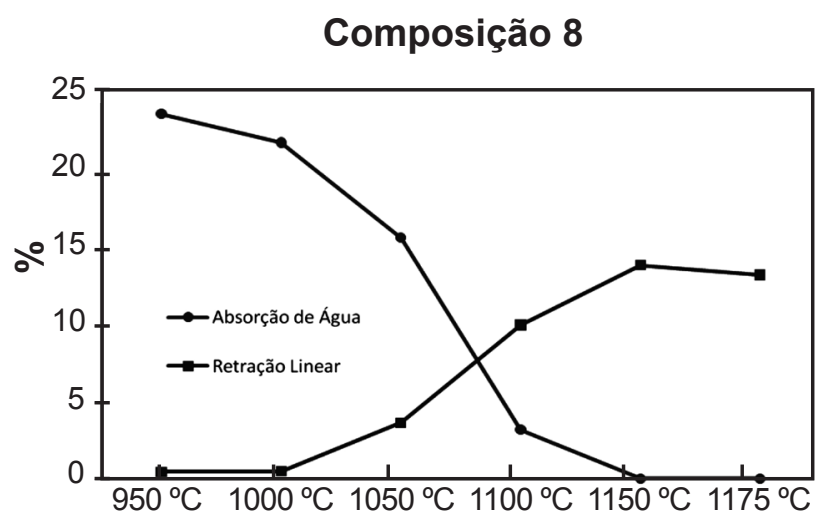

Figura 8: Gráfico de gresificação da massa de porcelanato de composição 8 (100\% nefelina e 100\% argilito Santa Gertrudes).

[Figure 8: Vitrification curves of porcelainized stoneware tile body of composition 8 (100\% nepheline and 100\% Santa Gertrudes mudstone).]
Gertrudes (ou composição 8): analisando a curva de gresificação para esta composição, Fig. 8, observa-se o comportamento de caráter mais acentuado. Queda abrupta da absorção de água a partir de $1000{ }^{\circ} \mathrm{C}$, com valores muito reduzidos a partir de $1150^{\circ} \mathrm{C}$. Tal fato é decorrente da maior quantidade de óxidos fundentes presentes nestas matériasprimas (nefelina e argilito).

Comparações entre as características de diferentes tipos de massas: a comparação das características cerâmicas após queima das massas formuladas foi realizada a partir de amostras selecionadas, sinterizadas com temperatura de patamar de queima de $1150{ }^{\circ} \mathrm{C}$, avaliando-se a possibilidade da redução do consumo de gás natural.

Porosidade aparente: as densidades a verde, após prensagem e secagem, para as amostras das composições escolhidas variaram em torno de 1,85 e $1,95 \mathrm{~g} / \mathrm{cm}^{3}$. Este valor está em acordo com os valores usualmente utilizados na indústria para a conformação de composições de grês porcelanato (em torno de 2,0 a 2,1 g/cm³). A Fig. 9 apresenta os resultados das porosidades aparentes em função da temperatura do patamar de queima para as massas selecionadas. O efeito da nefelina na densificação é bastante similar ao proporcionado pelo feldspato até a temperatura de $1050{ }^{\circ} \mathrm{C}$, e que em temperaturas superiores, a nefelina é mais efetiva e leva a uma redução significativa da porosidade. Por outro lado, o efeito do argilito iniciase a uma temperatura inferior $\left(1000{ }^{\circ} \mathrm{C}\right)$ e torna-se ainda mais acentuado em temperaturas maiores, levando a uma porosidade praticamente nula nas massas contendo nefelina, a partir de $1150{ }^{\circ} \mathrm{C}$.

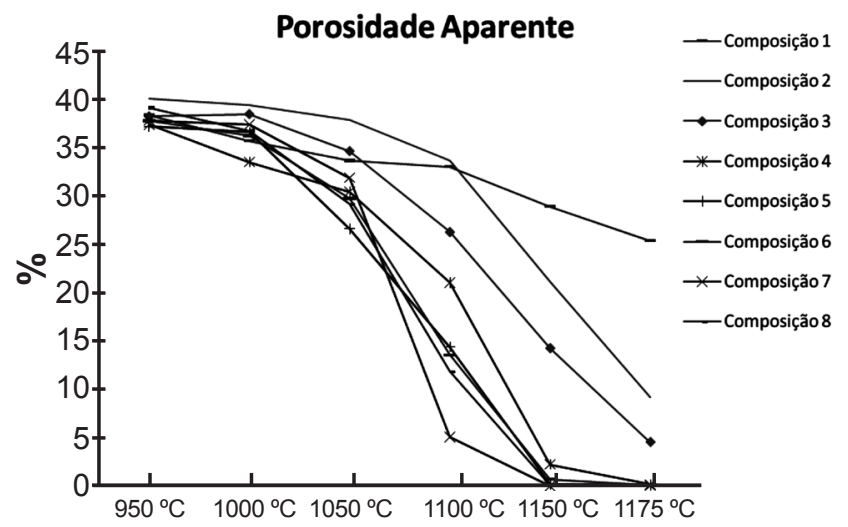

Figura 9: Porosidade aparente em função da temperatura de queima para composições de porcelanato contendo diferentes matériasprimas.

[Figure 9: Porosity as function of firing temperature for porcelainized stoneware tile compositions containing different raw materials.]

Resistência mecânica: os corpos-de-prova das composições contendo argila S. Simão apresentaram menor resistência que aqueles das composições contendo argilito de Santa Gertrudes (Fig. 10). Além disso, a resistência mecânica dos corpos-de-prova contendo feldspato é menor do que os corpos contendo nefelina. Estes comportamentos 
eram esperados devido à maior porosidade dos corpos-deprova contento argila S. Simão e feldspato, e os gráficos mostraram-se coerentes com os obtidos para as medidas de porosidade aparente (Fig. 9).

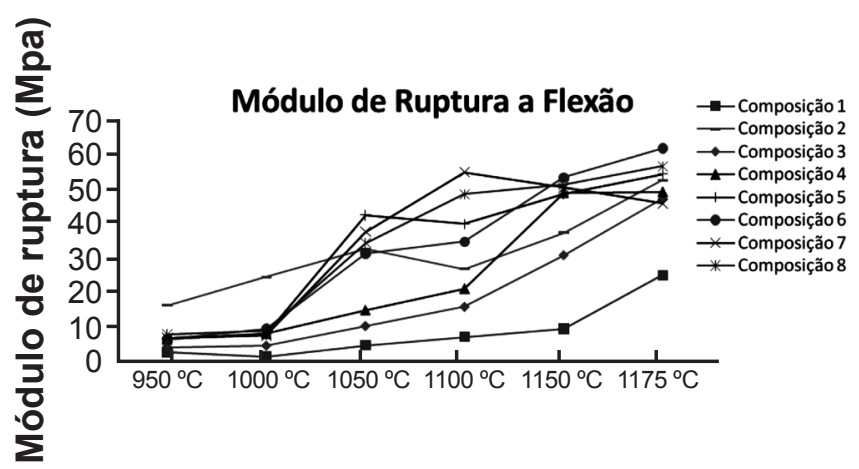

Figura 10: Curvas de variação do módulo de ruptura à flexão em função da temperatura de queima para composições de porcelanato contendo diferentes matérias-primas.

[Figure 10: Module flexural strength as a function of firing temperature for porcelainized stoneware tile compositions containing different raw materials.]

É importante ressaltar que, não só os defeitos e a porosidade do material afetaram a resistência mecânica, mas as fases desenvolvidas e o teor de fase vítrea certamente também contribuíram. Os valores apresentados foram obtidos pela média de 4 corpos-de-prova para cada temperatura de queima e os desvios padrão não ultrapassaram $10 \%$ para todas as formulações.

Dilatação térmica: com o objetivo de se observar o comportamento das principais formulações $(1,3,4,8)$ em função da temperatura de queima, foi realizado o ensaio dilatométrico, cujos resultados obtidos por meio das curvas de dilatação térmica estão apresentados nas Fig. 11. A composição contendo nefelina e argilito Santa Gertrudes (8) apresenta uma maior dilatação se comparada às outras composições. No entanto, apresenta o início de retração em torno de $830^{\circ} \mathrm{C}$, o que a leva a sinterizar em temperaturas mais baixas que as outras composições, conforme observado na curva de gresificação (Fig. 8). O efeito dos dois tipos de matérias-primas separadas também pode ser observado. Comparando-se as formulações 1 (contendo feldspato) e
3 (contendo nefelina) revela-se uma temperatura de início de retração inferior para a composição 3. Quanto ao tipo de argila utilizado, basta comparar as formulações 1 (contendo argila S. Simão) e 4 (argilito Santa Gertrudes), observandose maior coeficiente de dilatação térmica para a composição 4, com reduzida temperatura de início de retração.

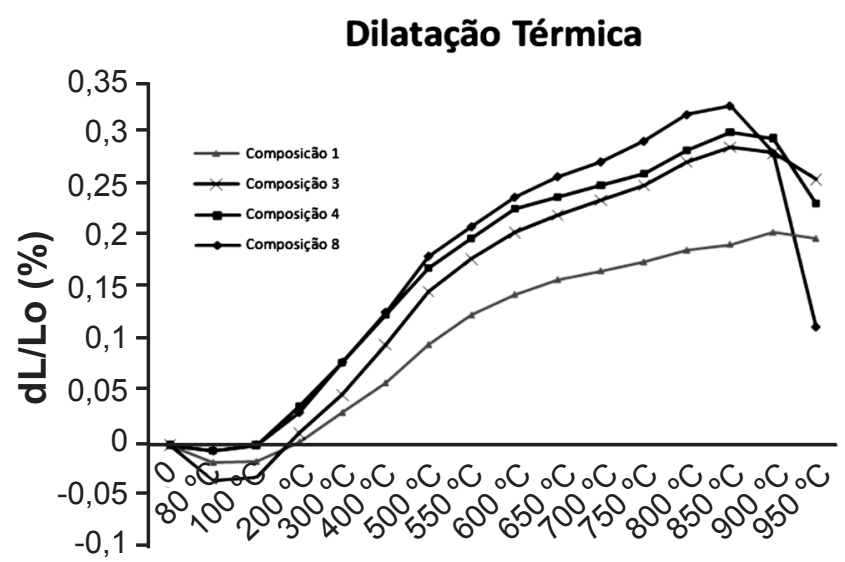

Figura 11: Curvas de dilatação térmica para composições de porcelanato contendo diferentes matérias-primas.

[Figure 11: Module Curves of thermal expansion for porcelainized stoneware tile compositions containing different raw materials.]

A Tabela $\mathrm{V}$ apresenta temperatura de início de retração para cada composição estudada obtidos pelo ensaio de dilatometria. Também são apresentados os coeficientes de expansão térmica linear na faixa de 200 a $800{ }^{\circ} \mathrm{C}$. Pode-se notar que se por um lado à presença de maior quantidade de fundentes na composição facilita o início da retração (processo de sinterização), por outro, ele eleva o coeficiente de expansão térmica linear.

Identificação de fases: com o objetivo de melhor analisar as características obtidas para cada composição de massa de porcelanato, dados os diferentes fundentes e possíveis reações deles durante a queima do material, foram realizados ensaios de difração de raios $\mathrm{X}$ e análise microestrutural para detecção e observação das fases desenvolvidas. As microestruturas foram obtidas por microscopia eletrônica de varredura por meio de elétrons secundários (SE). As amostras escolhidas para estas análises foram retiradas da superfície de fratura dos corpos-de-prova das composições

Tabela V - Temperatura de início de retração e coeficiente de dilatação térmica para massas de porcelanato contendo diferentes tipos e proporções de fundentes.

[Table V - Initial temperature of shrinkage and thermal expansion coefficient of porcelainized stoneware tile bodies containing different types and proportions of fluxing materials.]

\begin{tabular}{ccccccc}
\hline Composição & $\begin{array}{c}\text { Feldspato } \\
(\%)\end{array}$ & $\begin{array}{c}\text { Nefelina } \\
(\%)\end{array}$ & $\begin{array}{c}\text { Argila } \\
\text { S. Simão } \\
(\%)\end{array}$ & $\begin{array}{c}\text { Argilito } \\
\text { S. Gertrudes } \\
(\%)\end{array}$ & $\begin{array}{c}\text { Temp. início } \\
\text { de retração }\left({ }^{\circ} \mathrm{C}\right)\end{array}$ & $\begin{array}{c}\alpha \\
10^{-6}{ }^{\circ} \mathrm{C}^{-1}\end{array}$ \\
\hline 1 & 45,00 & 0,00 & 30,00 & 0,00 & 900 & 5,41 \\
3 & 0,00 & 45,00 & 30,00 & 0,00 & 845 & 7,50 \\
4 & 45,00 & 0,00 & 0,00 & 30,00 & 850 & 7,16 \\
8 & 0,00 & 45,00 & 0,00 & 30,00 & 830 & 8,33 \\
\hline
\end{tabular}




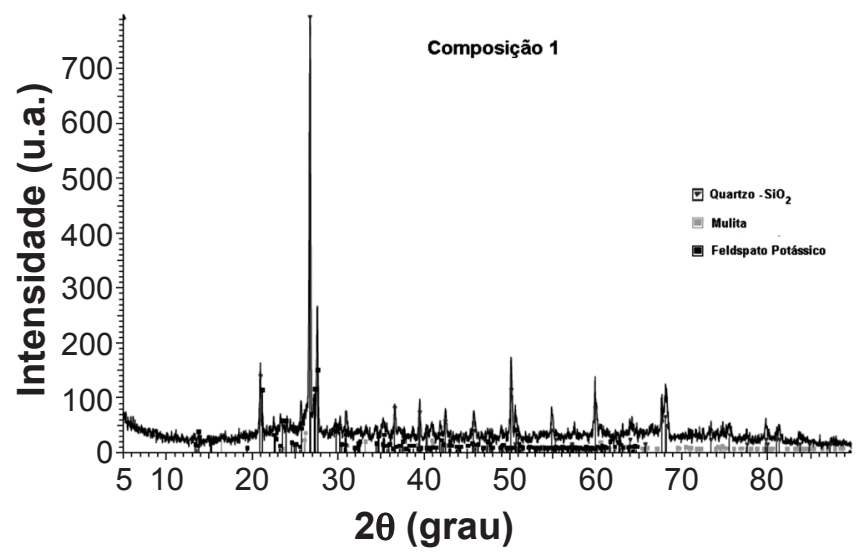

Figura 12: Difratograma de raios $\mathrm{X}$ da amostra de porcelanato contendo $100 \%$ feldspato e $100 \%$ argila S. Simão (composição 1) após queima a $1150{ }^{\circ} \mathrm{C}$.

[Figure 12: X-ray diffraction pattern of porcelainized stoneware tile sample containing $100 \%$ feldspar and $100 \%$ S. Simão clay (composition 1) after firing $1150^{\circ} \mathrm{C}$.]

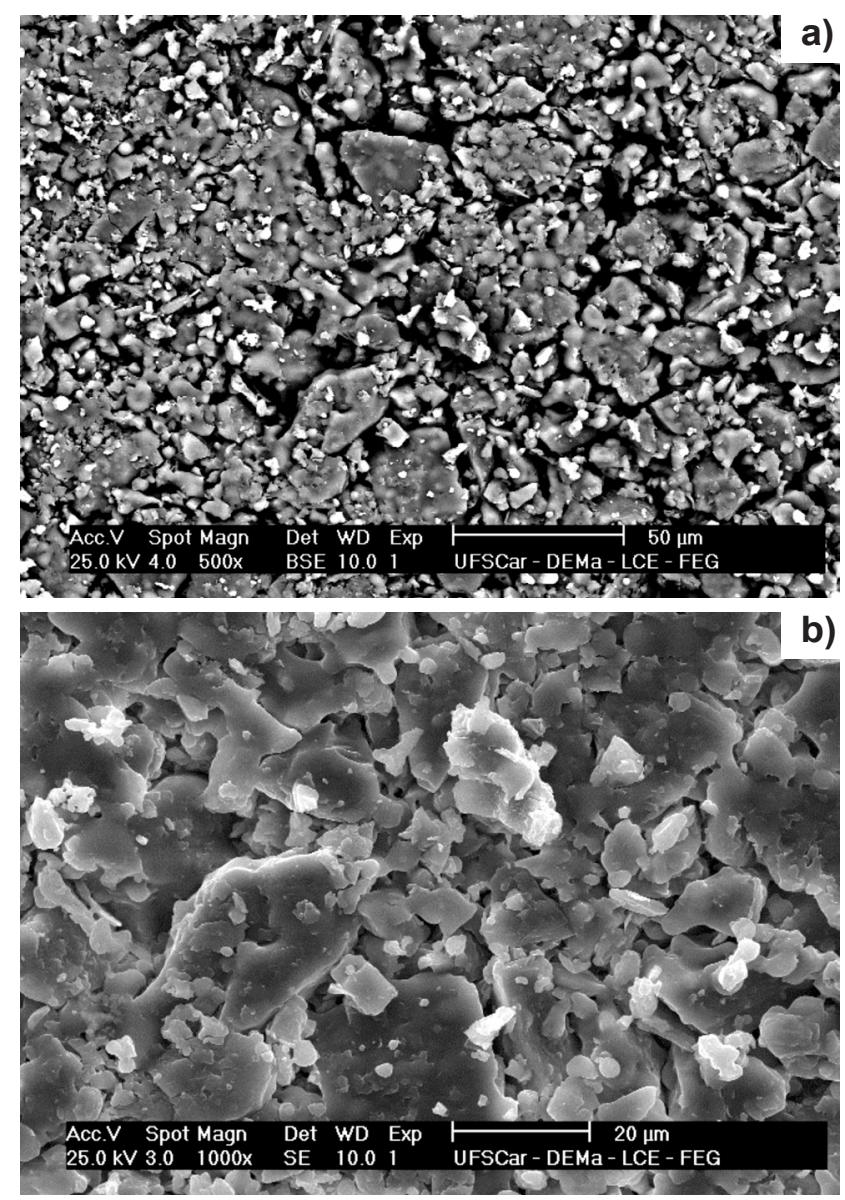

Figura 13: Micrografias obtidas em microscópio eletrônico de varredura da superfície de fratura da amostra da composição de porcelanato contendo $100 \%$ feldspato e $100 \%$ argila S. Simão (composição 1) após queima a $1150{ }^{\circ} \mathrm{C}$ : (a) aumento $500 \mathrm{X}$, (b) aumento 1000X.

[Figure 13: Scanning electron microscopy micrographs of fractured surface of porcelainized stoneware tile sample containing $100 \%$ feldspar and $100 \% \mathrm{~S}$. Simão clay (composition 1) fired at $1150{ }^{\circ} \mathrm{C}$ : (a) increase of $500 \mathrm{X},(\mathrm{b})$ increase of $1000 \mathrm{X}$.] selecionadas. A Fig. 12 apresenta o difratograma de raios X da massa de porcelanato da composição 1 (100\% feldspato). É possível observar a presença das fases quartzo, mulita e feldspato. A presença de feldspato indica que ele não fundiu totalmente (ou se decompôs em fase líquida), evidenciando que, com o aumento de temperatura, a porosidade poderia ser ainda mais reduzida; a composição 1 apresentou uma porosidade aparente em torno de $28 \%$ a $1150{ }^{\circ} \mathrm{C}$ (Fig. 9). A porosidade residual pode ser observada na micrografia obtida da análise microestrutural, apresentada na Fig. 13.

A Fig. 14 apresenta o difratograma de raios $\mathrm{X}$ da massa de porcelanato da composição 3 (100\% nefelina). É possível observar a presença de quartzo, anortita, albita, mulita, cianita e silicato de cálcio e sódio; tal modificação é proveniente da introdução de nefelina na formulação, contendo maior quantidade de sódio e potássio quando comparada ao feldspato potássico. Detalhes da microestrutura, apresentados nas micrografias da Fig. 15, mostram a porosidade residual e a presença de poros fechados em uma matriz vítrea. Vale lembrar que a presença de poros fechados é uma característica indesejada uma vez que, além de afetar a resistência mecânica do material, eles aumentam a susceptibilidade do produto ao manchamento durante o uso.

Por meio da difração de raios $\mathrm{X}$ da composição 4, que contêm feldspato e argilito Santa Gertrudes em sua formulação, é possível observar a presença das fases cristalinas quartzo, mulita, feldspato potássico, e hematita (Fig. 16). O óxido de ferro (hematita) é oriundo do argilito e o feldspato, novamente, indica fusão parcial da matériaprima.

A análise microestrutural das amostras da massa de composição 4 após sinterização a $1150{ }^{\circ} \mathrm{C}$, confirmou a elevada quantidade de fase vítrea do material, cujas micrografias são apresentadas na Fig. 17. É possível observar que, pelo aspecto geral, existe uma porosidade residual (poros fechados).

A Fig. 18 apresenta o difratograma de raios X da massa de porcelanato da composição 8 (100\% nefelina e $100 \%$ argilito Santa Gertrudes). Assim como a composição 4, observa-se a presença de quartzo, mulita, feldspato potássico e hematita. Detalhes da microestrutura, apresentados nas micrografias da Fig. 19, revelam uma grande quantidade de fase vítrea.

Em síntese, pode-se dizer que a formação de fases majoritárias nas séries de massas está muito relacionada com a análise química destas matérias-primas, uma vez que os demais componentes das massas (caulim, quartzo e talco) foram mantidos constantes para todas as composições. Isto é, o feldspato gera a fase cristalina no material final (após sinterização), mas sua decomposição não é total, resultando fase vítrea; a nefelina leva à formação de novas fases (anortita, albita, etc), e devido a sua elevada fundência não permanece como fase remanescente; é evidente que a presença do argilito Santa Gertrudes resulta em bandas características de material não cristalino e favorece a formação de quartzo e hematita. 


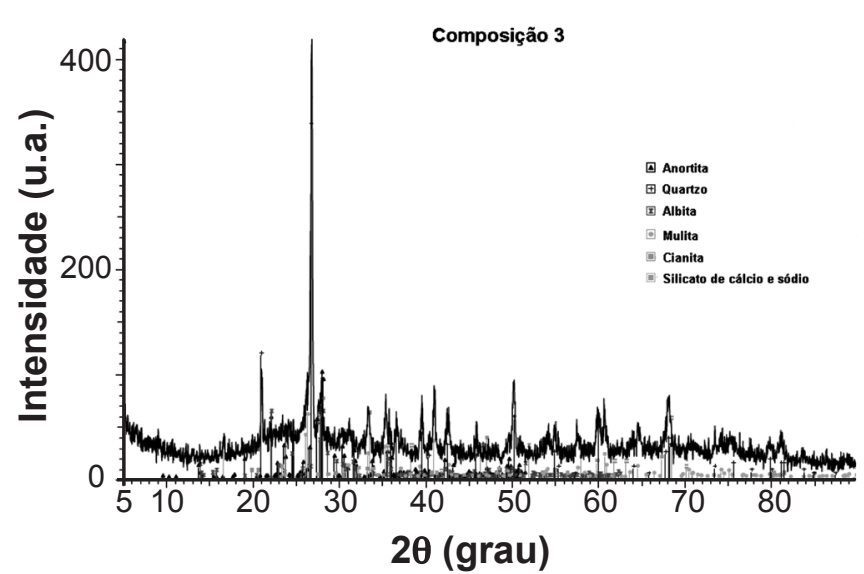

Figura 14: Difratograma de raios $\mathrm{X}$ da amostra de porcelanato contendo $100 \%$ nefelina e $100 \%$ argila S. Simão (composição 3) após queima a $1150{ }^{\circ} \mathrm{C}$.

[Figure 14: X-ray diffraction pattern of porcelainized stoneware tile sample containing $100 \%$ nepheline and $100 \%$ S. Simão clay (composition 3) after firing $1150^{\circ} \mathrm{C}$.]
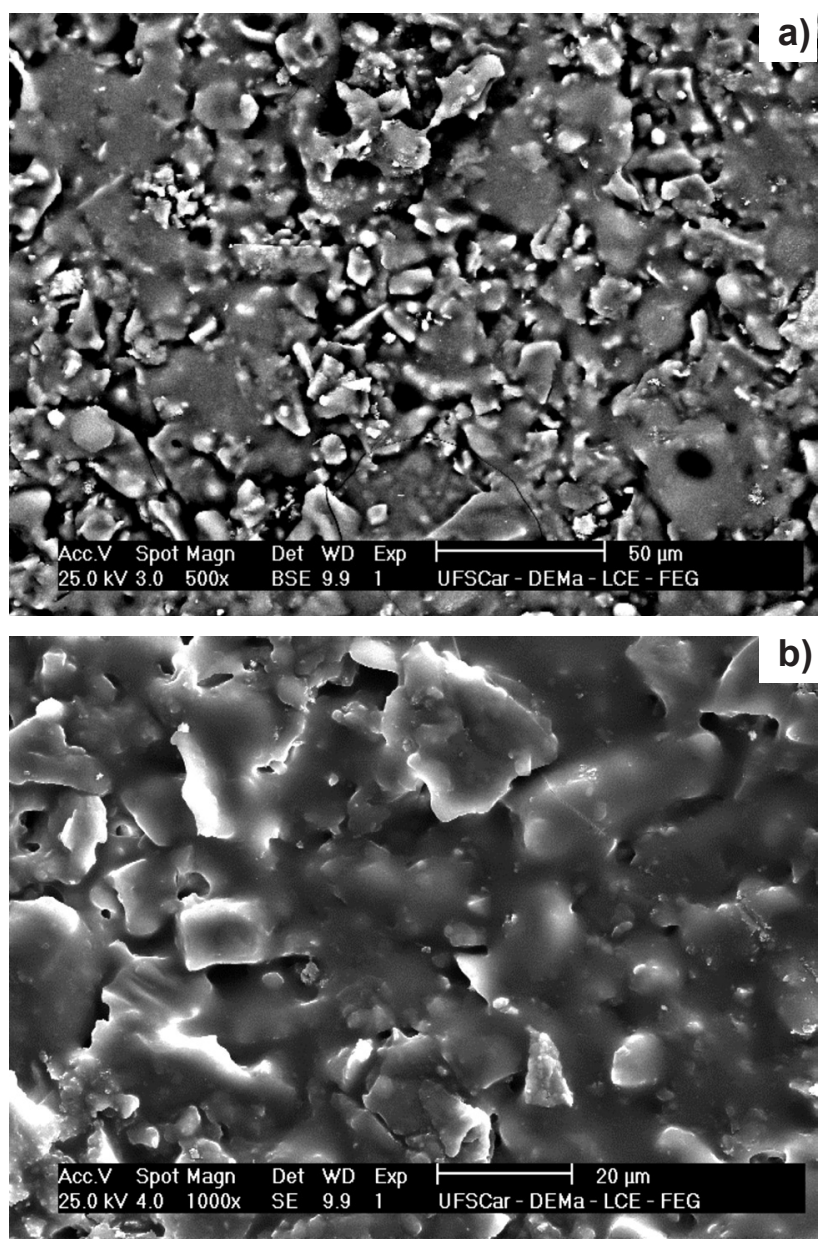

Figura 15: Micrografias obtidas em microscópio eletrônico de varredura da superfície de fratura da amostra da composição de porcelanato contendo 100\% nefelina e 100\% argila S. Simão (composição 3) após queima a $1150^{\circ} \mathrm{C}$ : (a) aumento $500 \mathrm{X}$, (b) aumento $1000 \mathrm{X}$.

[Figure 15: Scanning electron microscopy micrographs of fractured surface of porcelainized stoneware tile sample containing $100 \%$ nepheline and $100 \% \mathrm{~S}$. Simão clay (composition 3) fired at $1150{ }^{\circ} \mathrm{C}$ : (a) increase of 500X, (b) increase of 1000X.]

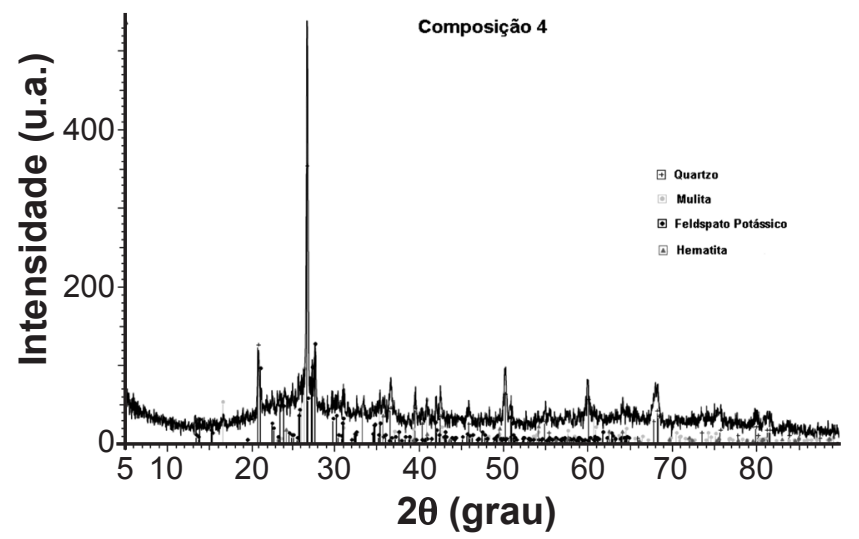

Figura 16: Difratograma de raios $\mathrm{X}$ da amostra de porcelanato contendo $100 \%$ feldspato e $100 \%$ argilito Santa Gertrudes (composição 4) após queima a $1150{ }^{\circ} \mathrm{C}$.

[Figure 16: X-ray diffraction pattern of porcelainized stoneware tile sample containing 100\% feldspar and 100\% Santa Gertrudes mudstone (composition 4) after firing $1150{ }^{\circ} \mathrm{C}$.]
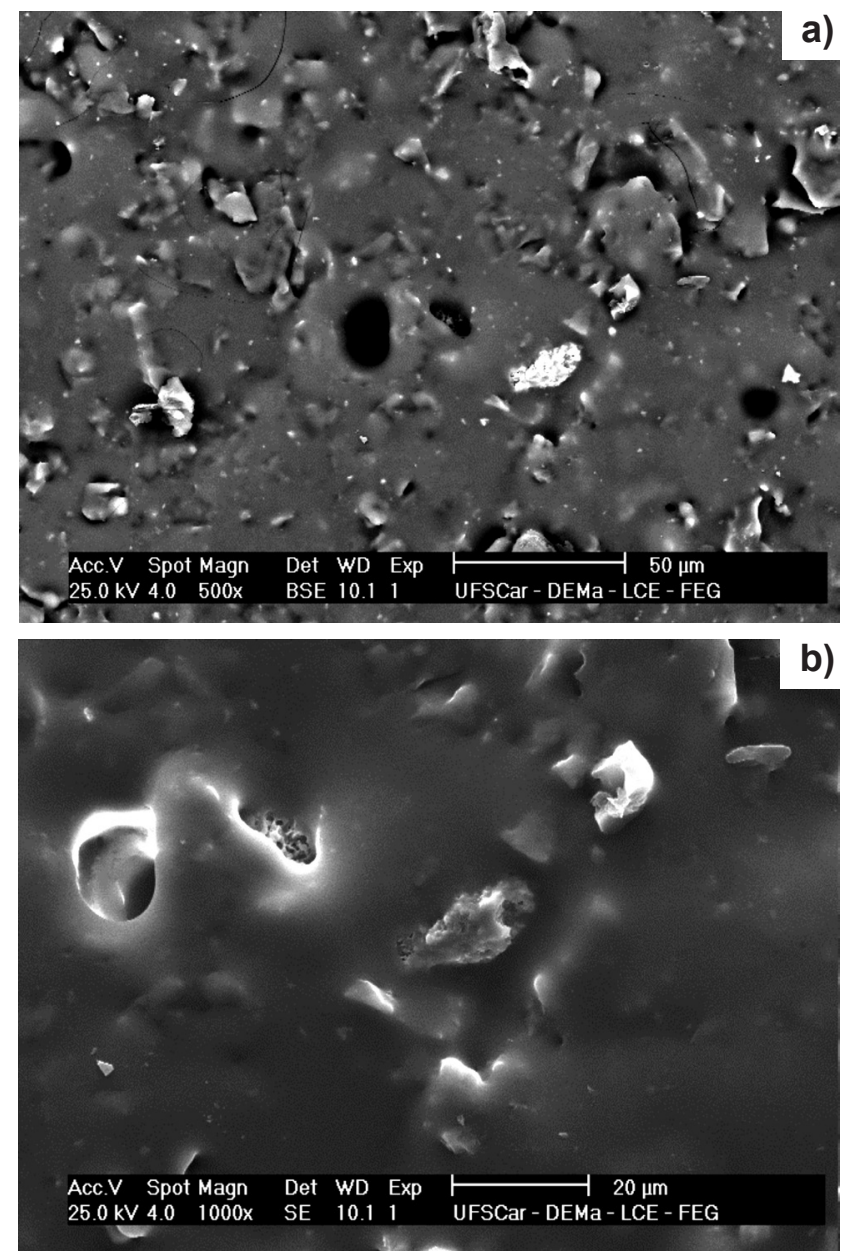

Figura 17: Micrografias obtidas em microscópio eletrônico de varredura da superfície de fratura da amostra da composição de porcelanato contendo 100\% feldspato e 100\% argilito Santa Gertrudes (composição 4) após queima a $1150{ }^{\circ} \mathrm{C}$ : (a) aumento $500 \mathrm{X}$, (b) aumento $1000 \mathrm{X}$. [Figure 17: Scanning electron microscopy micrographs of fractured surface of porcelainized stoneware tile sample containing $100 \%$ feldspar and 100\% Santa Gertrudes mudstone (composition 4) fired at $1150{ }^{\circ} \mathrm{C}:(\mathrm{a})$ increase of $500 \mathrm{X},(\mathrm{b})$ increase of $1000 \mathrm{X}$.] 


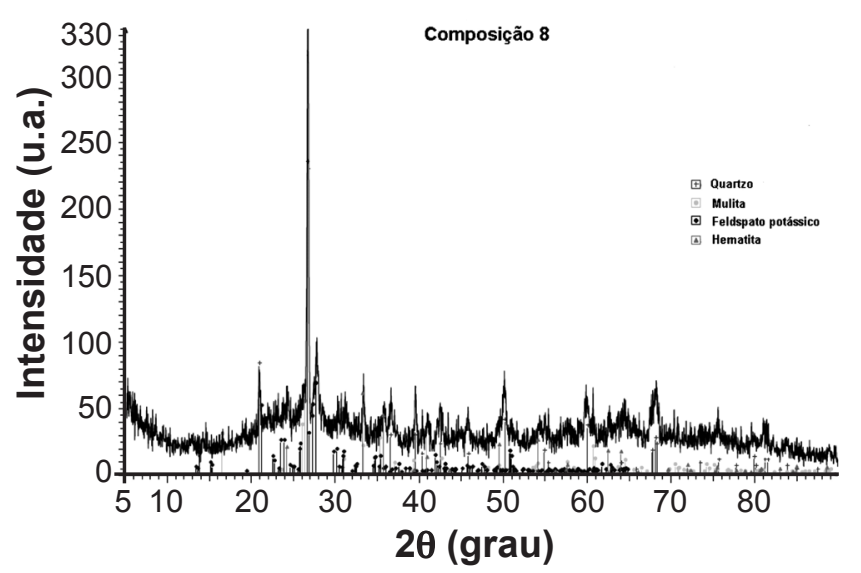

Figura 18: Difratograma de raios $\mathrm{X}$ da amostra de porcelanato contendo $100 \%$ nefelina e $100 \%$ argilito Santa Gertrudes (composição 8) após queima a $1150{ }^{\circ} \mathrm{C}$.

[Figure 18: X-ray diffraction pattern of porcelainized stoneware tile sample containing 100\% nepheline and 100\% Santa Gertrudes mudstone (composition 8) after firing $1150{ }^{\circ} \mathrm{C}$.]
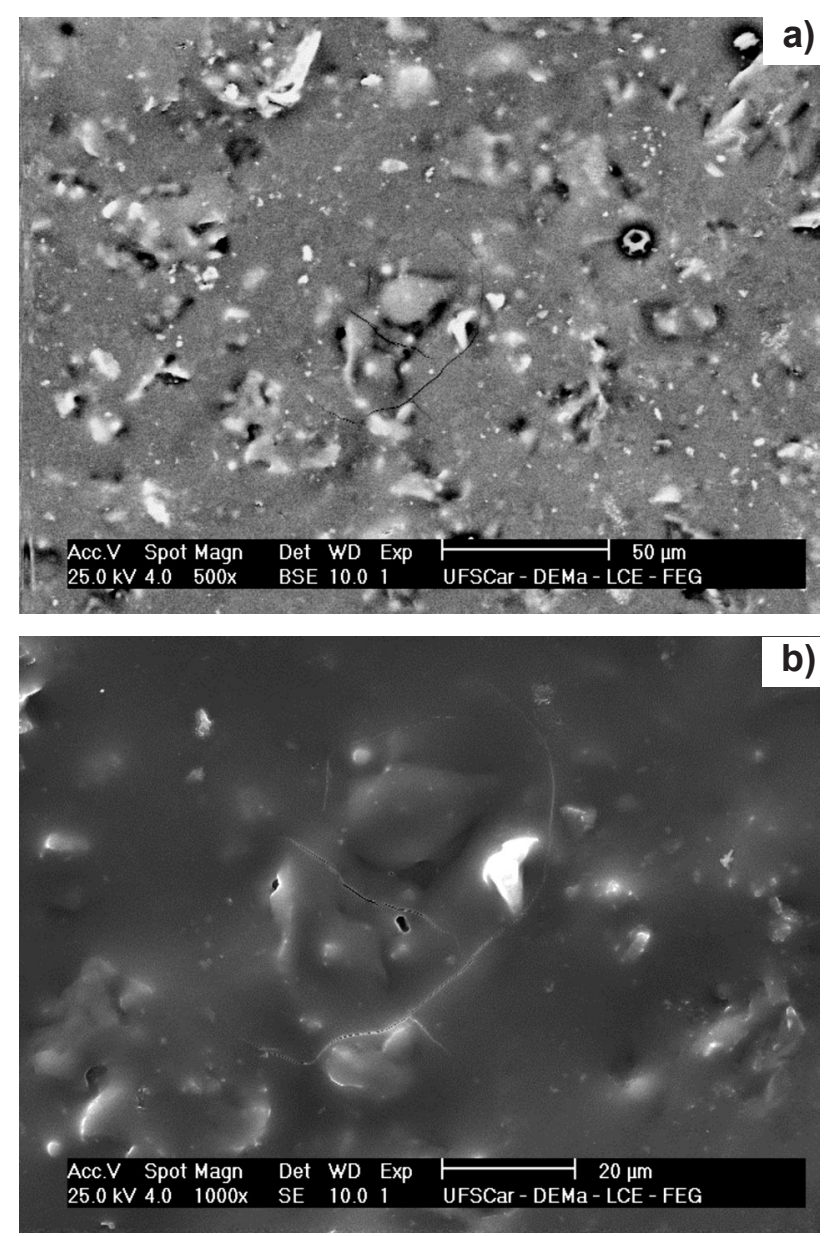

Figura 19: Micrografias obtidas em microscópio eletrônico de varredura da superfície de fratura da amostra da composição de porcelanato contendo $100 \%$ nefelina e $100 \%$ argilito Santa Gertrudes (composição 8) após queima a $1150{ }^{\circ} \mathrm{C}$ : (a) aumento 500X, (b) aumento 1000X.

[Figure 19: Scanning electron microscopy micrographs offractured surface of porcelainized stoneware tile sample containing $100 \%$ nepheline and 100\% Santa Gertrudes mudstone (composition 8) fired at $1150{ }^{\circ} \mathrm{C}:$ ( a) increase of $500 \mathrm{X},(\mathrm{b})$ increase of 1000X.]

\section{CONCLUSÕES}

A introdução de nefelina no sistema feldspato-argilacaulim-quartzo-talco, não afeta significativamente a distribuição do tamanho de partículas da massa, mas reduz de forma considerável os valores de absorção de água até a temperatura de $1150{ }^{\circ} \mathrm{C}$. Esta redução, porém, não atinge o valor estabelecido pela norma técnica ABNT NBR $15.463 / 2007(<0,5 \%$ para porcelanatos esmaltados). Devido ao fato das características físico-químicas da nefelina serem muito semelhantes às do feldspato, ela não causa alterações significativas nas curvas de gresificação, porosidade aparente em função da temperatura de queima, e na resistência mecânica final. A nefelina não modifica drasticamente a temperatura de início de sinterização apesar da sua maior fundência em relação ao feldspato. Composições com a nefelina e feldspato/nefelina apresentam praticamente a mesma expansão térmica linear onde os valores dos coeficientes de dilatação térmica estão muito próximos. A presença do argilito Santa Gertrudes na massa de porcelanato substituindo a argila S. Simão, interfere na etapa de moagem e, para as mesmas condições de processo, resulta em massas com diâmetro médio de partículas superiores aos diâmetros das massas que contêm a argila Ball-clay. $\mathrm{O}$ argilito, que apresenta características físico-químicas distintas da argila S. Simão, reflete em alterações nas curvas de gresificação (queda mais acentuada para as curvas de absorção de água, atendendo à norma técnica para patamares de queima com valor inferior), podendo-se reduzir a temperatura de sinterização em torno de $50{ }^{\circ} \mathrm{C}$ (redução de custo do produto final), o que também resulta em maiores valores de resistência mecânica após queima (valores superiores a 45 $\mathrm{MPa}$ ). Além disso, a presença do argilito eleva os valores do coeficiente de expansão térmica linear quando presente nas massas contendo feldspato e/ou nefelina (em torno de 30\%), e promove a formação de quartzo e hematita (observado nos difratogramas), principalmente.

\section{REFERÊNCIAS}

[1] Associação Nacional dos Fabricantes de Cerâmicas, Catálogo informativo sobre o panorama da indústria cerâmica, S. Paulo, ANFACER (2009).

[2] A. O. Constantino, S. E. S. Rosa, A. R. Corrêa, Panoramas do setor de revestimento cerâmico, acesso em 11/2010, $<$ http://www.bndes.gov.br/SiteBNDES/export/sites/default/ bndes_pt/Galerias/Arquivos/conhecimento/relato/rs_rev_ ceramicos.pdf $>$. (2006)

[3] A. P. Luz, S. Ribeiro, Uso de pó de vidro como fundente para produção de grês porcelanato, Revista Matéria 13, 1 (2008) 96.

[4] M. M. Melo, Formulação e caracterização de massa de grês porcelanato preparadas a partir de matérias-primas naturais do Rio Grande do Norte, com adição de chamote de telhas, Diss. Mestrado em Engenharia Mecânica, Departamento de Engenharia Mecânica, Universidade Federal do Rio Grande do Norte, Rio Grande do Norte, RN (2006) 136 p. 
[5] G. Biffi, Grês porcelanato: manual de fabricação $e$ técnicas de emprego, $3^{\text {a }}$ Ed. Rio Claro, Faenza Editrice do Brasil (2002).

[6] ABNT - Associação Brasileira de Normas Técnicas, NBR 15.463, Placas cerâmicas para revestimento - porcelanato, Rio de Janeiro, RJ (2007).

[7] A. Salem, Dilatometeric study of shrinkage during sintering process for porcelain stoneware body in presence of nepheline syenite, J. Mater. Processing Tech. 209, 3 (2009) 1240.

[8] A. P. N. Oliveira, Grês porcelanato: aspectos mercadológicos e tecnológicos, Cerâmica Industrial 3, 3 (1998) 34.

[9] S. J. S. Arantes, A porosidade e manchamento de placas de grês porcelanato, Diss. Mestrado em Engenharia de
Materiais, Universidade Federal de S. Carlos, S. Carlos, SP (2001).

[10] SACMI IMOLA, Gres fine porcellanato, Imola, Itália (1996).

[11] E. Quinteiro, Utilização de frita devitrificável do sistema $\mathrm{SiO}_{2}-\mathrm{Al}_{2} \mathrm{O}_{3}-\mathrm{ZnO}$ como fundente na formulação de grês porcelanato, Anais do $44^{\circ}$ Congresso Brasileiro de Cerâmica, S. Pedro, SP (2000).

[12] F. G. Llorens, Matérias-primas fundentes para a fabricação de grês porcelanato, Cerâmica Informação 9 (2000).

[13] C. Gibertoni, P. I. Paulin, M. R. Morelli, Caracterização de cerâmicas sinterizadas por fluxo viscoso, Cerâmica $\mathbf{5 1}$, 320 (2005) 331.

(Rec. 11/02/2011, Rev.04/10/2011, Ac. 16/10/2011) 